\title{
CROSS-CULTURAL COMPARISON OF COMPANY ORGANIZATION STRUCTURE
}

\author{
Bakri Osman Hamad, Klaus-Dieter Fröhner \\ Institute of Ergonomics, University of Technology Hamburg Harburg, \\ Eissendorferstr. 40, 21073 Hamburg, Germany
}

This study tends to quantify some differences of developed and developing countries in the field of human resources. Due to different social and cultural milieus, no global solution is available to fit each country. This fact necessitates a special examination for countries according to their cultural context. In this part of the study, the cultural and social influential elements of the working force in a developing country were examined. The specific elements of satisfaction and production driving force with accordance with the motivation factors were defined. Variables that are most associated with individual performance, behavior and social structure that govern the inter-personnel relations were specified.

\section{INTRODUCTION}

In today's global economy, the standards of production are set-up either by the western or eastern developed countries. The newly industrialized countries have adapted these strategies without developing proceedings of their own. Today there is only little focus on the least developing countries (e.g. Africa and Latin America). If we look at the global economy, as an economy of one world, we should look also at this part of the world in order to promote the development in these countries.

Because the standards of production were set-up in industrialized nations, as a dominant world in this area, they were based on theories and findings that match their settings. One part of these standards is the explicit and implicit improvement of work performance according to the guidelines of motivation theories set by Herzberg and Maslow. These theories were extensively examined and applied in USA and western societies. But even though they are not automatically applicable in its entire terms, for example, for the Chinese society (Nevis 1983). These findings necessitate a re-examining of such theories so as to fit other culture specific terms. Maslow's pyramid of needs and Herzberg's hygiene and motivation factors, both alike, were set up according to individualistic societies culture. This fact makes their application in loyal and collective societies questionable. In Maslow's pyramid of needs, for the north American, the physiological need comes first, followed by safety need, social belonging, self esteem and at the top comes self-actualization in individual development, whereas for the Chinese, belonging comes first, followed by physiological need, then safety and at the top of the pyramid comes selfactualization in service to society

So the ultimate goal of this study is to equip and qualify managers with wide organizational prospects in the field of human factors, humanrelations and human-related aspects by studying the real situation in developing countries and looking at these examples in the context of society.

\section{JUSTIFICATION OF THE STUDY}

Literature tells that managers in developing countries are often lacking in specific industry knowledge with insufficient experience and training which make them lack clear mission or sense of direction for subordinates. Adding up to the low self-motive, strict and hierarchical controls have effectively prevented workers from developing new skills and using their own work initiative. It is seen that the intensive division of labor has inevitably promoted frustrations amongst workers who are not content with a job that leaves little room for initiative and responsibility (Blunt, 1993; Kiggundu 1989 in Blunt, 1992; Burawoy 1972). (Ketchum, 1984) summarized some of African countries problems in the following: low productivity, poor worker management relations, high absenteeism, low payment, complaints of bias in promotion, selection, and reward. Ketchum suggested that, should the potential socio-technical or any structural adjustment and redesign be achieved, attention must be given to working force material rewards. 
(Kanawaty, 1981) study revealed that, among workers, education levels seem not to be a factor in determining success or failure of work reorganization, because they are willing and capable of learning on the job.

Because these findings were based on the experience out of case-studies, it is necessary to set up an empirical study to shade light on the situation of the work-force in developing countries.

\section{SUBJECTS}

139 subjects were interviewed in this study. 30 managers and 49 workers were questioned in 1995 and 60 workers in 1997. All workers in both surveys were randomly selected. Focus of this study will be on the findings of the results from the survey that was carried out in 1995.

In the first survey a textile state-firm and a soft drink private-firm were investigated. Both selected companies set an example for the industry sector in Sudan. Textile, as labor-intensive companies, have been established to process the main agricultural product, whereas soft drink companies to meet the high demand of soft drink in a sub-Saharan country.

49 workers were asked, 19 of them were working in the private-owned soft drink company and 30 workers in the state-owned textile company. Gender distribution was as follows: 11 were women ( 10 are in the state firm and 1 in the private firm) and 38 were men ( 20 in the state firm and 18 in the private firm). 11 of the interviewed were single, 6 of them work for the private firm and 5 work for the state firm. From the 38 who have families, 13 work for the private firm and 25 for the state firm.

Due to limited numbers of managers and leading staff in the two firms, beside the above mentioned firms, managers from other additional companies (private-owned textile, soft drink privateowned, and two joint-ventures) were interviewed. In total 30 managers and leading staff participated in this study.

\section{METHOD AND RESEARCH TECHNIQUES}

Two questionnaires were designed for labor and managing personnel. Workers questionnaire addressed general information, such as age structure, education, nature of the job, working experience and some other related information. Part of the questions covered working moral, job security, job satisfaction, job content, and tendency to quit the job. Social engagement, social relation and working relation as well as general working atmosphere were examined.

The managers' and leading staff's questionnaire covers general and personal information such as qualification, working experience, training obtained and age. Some questions examined company activities, working hours, work plans, scheduling of activities, working force classification and distribution within the firm as well as production problems. Some of the questions cover the technical side and technical related issues.

SPSS and SAS were used to test the significance of the tests. With the SPSS statistical package, ChiSquare-Test and Fisher-Exact-Test were performed for the independent variables position (between managers and workers), firm (private and state), and position (within workers with responsibilities as group or shift leaders, and workers without responsibilities). With the SAS statistical package, Analysis of Variance (ANOVA) and a post hoc Student-Neuman-Keuls-Test (SNK) were performed for some of the independent variables.

\section{RESULTS AND ANALYSIS}

Because of the small number of the selected sample, field tests were performed, where Chi-SquareTest and Fisher Exact-Test were used to test the significance of the results of the 1995 survey between labors $(\mathrm{N}=49)$ and managers $(\mathrm{N}=30)$, within workers (workers $\mathrm{N}=37$; group leaders $\mathrm{N}=9$, shift leaders $\mathrm{N}=3$ ) and by firms (state and private).

\section{By Position (Between managers and workers)}

One of the determining success factors in modern management is seen in the information and transparency of organization for all working force, through which the workers will become more identified and integrated with their companies. This study tackled this problem and the results showed that managers are expecting more information about company activities than workers. Workers are significantly different from managers for this dependent variable at a significance level of $\alpha=$ 0.002 .

By this it can be stated that the workers, who in general have a low educational level (but a maximum up to 12 grade) and a maximum vocational training of 12 months, are satisfied with their information, where 
on the other hand the managers are lacking in information for their subordinates (Figure 1).

\begin{tabular}{|c|c|c|c|}
\hline \multicolumn{4}{|c|}{ How do you evaluate your information about } \\
company activities? \\
\hline position & positive & neutral & negative \\
\hline workers & 18 & 19 & 12 \\
\hline managers & 4 & 7 & 19 \\
\hline \multicolumn{4}{|c|}{$\chi_{2 \times 3}^{2}=12,2 ; \alpha=0,002$} \\
\hline
\end{tabular}

Figure 1: Significant test for information about company activities

For another dependent variable ,What does motivate you more to improve your performance?" there was no significant difference between the two groups. But the majority of workers and managers signified the importance of financial incentives more than getting more training. This was clear since most of the workers were practicing more than one job at a time in order to maintain their families with the basic needs (Figure 2).

\begin{tabular}{|c|c|c|}
\hline \multicolumn{3}{|c|}{ What does motivate you more to improve } \\
your performance? \\
\hline \multicolumn{3}{|c|}{ answers } \\
position & training & incentives \\
\hline workers & 5 & 44 \\
\hline managers & 7 & 23 \\
\hline \multicolumn{2}{|c|}{$\chi_{2 \times 2}^{2}=2,5 ; \alpha=0,11$} \\
\hline
\end{tabular}

Figure 2: Significant test for the dependent variable „What does motivate you more to improve your performance?"

The financial incentives play an important role for workers and managers as a mean to fulfill their basic needs. This is an important element to look for, when trying to realize company strategies.

\section{By Firms}

Chi-Square and ANOVA tests were also performed for the independent variable firm. In the following test it is shown that workers in state firms are more ready to quit their jobs. The reason for this is seen in the very unsatisfactory economical situation because of the very low income.

The difference between private and state firms is seen in the difference of the social structure. In the private companies there are obviously strong loyal structures and close social relations which override the wish to quit the job. Even though most of the workers $(70 \%)$ explained their desire to quit their jobs. There was significant difference between private and state workers to quit the job (Figure 3).

\begin{tabular}{|c|c|c|}
\hline \multicolumn{3}{|c|}{ Readiness to quit the job } \\
\hline \multicolumn{3}{|c|}{ answers } \\
firm & no & yes \\
\hline private & 2 & 17 \\
\hline state & 13 & 17 \\
\hline \multicolumn{2}{|c|}{$\chi_{2 \times 2}^{2}=5,9 ; \quad \alpha=0,015$} \\
\hline
\end{tabular}

Figure 3: Significant test for readiness to quit the job

It is also shown that the percentage of the workers with other jobs is much higher in state firm than that in the private firm, but no significant difference can be shown (Figure 4).

\begin{tabular}{|c|c|c|}
\hline \multicolumn{3}{|c|}{ Do you practice other jobs beside this one? } \\
\hline \multicolumn{3}{|c|}{ answers } \\
firm & no & yes \\
\hline private & 9 & 10 \\
\hline state & 10 & 20 \\
\hline \multicolumn{2}{|c|}{$\chi_{2 \times 2}^{2}=0,97 ;$} & $\alpha=0,33$ \\
\hline
\end{tabular}

Figure 4: Significant test ,having other job by type of firm"

ANOVA test showed that there are significant differences between the two firms (state firm $\mathrm{N}=30$ and private firm $N=19$ ) for the dependent variables working experience (state firm workers have longer working experience that those in private firm, $\mathrm{F}=$ 17.20 with p-value $=0.0002<0.05$ ), duration of training (state firm workers have longer training duration than those in private firm, $F=16.76$ with $p$ value $=0.0002<0.05$ ), but no significant difference for the dependent variable school attended and having other jobs. A post hoc Student-Neuman-Keuls-Test for the independent variable firm proved the same results.

\section{By Position (within workers)}

Chi-Square and ANOVA tests were performed to test the differences within the randomly selected group of the two firms (workers $\mathrm{N}=37$; group leaders $\mathrm{N}=9$, shift leaders $\mathrm{N}=3$ ). 
Chi-Square test showed that no significant difference for the dependent variable having other job with regard to position in the firm (Figure 5).

\begin{tabular}{|c|c|c|}
\hline \multicolumn{3}{|c|}{ Do you have other jobs beside this one? } \\
\hline \multicolumn{3}{|c|}{ answers } \\
position & no & yes \\
\hline $\begin{array}{c}\text { workers without } \\
\text { leading position }\end{array}$ & 13 & 24 \\
\hline $\begin{array}{c}\text { workers, as shift } \\
\text { or group leader }\end{array}$ & 6 & 6 \\
\hline \multicolumn{3}{|c|}{$\chi_{2 \times 2}^{2}=0,84 ; \alpha=0,36$} \\
\hline
\end{tabular}

Figure 5: Significant test ,position in firm and having other jobs"

Also ANOVA test showed that no significant differences for all dependent variables (having other job, job satisfaction, and job security) with respect to the independent variable position in the firm were found. SNK test showed the same results for workers holding different positions in the two firms.

This means that it is a general attitude and necessity to realize additional activities even for workers with leading position.

\section{CONCLUSION}

Although the situation seems to be ambivalent at a first glance, we think that there are good chances to promote and accelerate the development of the least industrialized countries because of the following:

- If concentrating on Herzberg and Maslow we will have a deadlock because of the low income in the main job and unsatisfactory job content. This is blocking any further development of the work force.

- The low income leads to the fact that $60 \%$ of the work force have jobs beside their main job and hereby are not effective.

- Furthermore the strict hierarchical controls tend to hinder the workers from not to ask about more information in order to acquaint themselves with a broader view of the work situation.
When also introducing Argyris theory into the set of dominant motivation theories there seems to be a solution for an initiative start-up:

- Managers possess high qualification which makes the realization of on the job training for workers possible.

- The low utilization capacity, due to many reasons, offers a good chance for both workers and managers to up-grade their qualification.

- The good social-work relation facilitates excellent climate for homogeneous and self-monitored working groups.

\section{References}

Blunt, P. / Jones, M. L. / Richard, D.: Managing Organizations in Africa:

Readings, Cases, and Exercises. Berlin: Walter de Gruyter, 1993

Blunt, P. / Jones, M. L.:

Managing Organizations in Africa: Walter de Gruyter, Berlin New York, 1992

Burawoy, $\mathrm{M}$.

Another look at the mine-worker. African social research, 14, p. 139-87, 1972

Hamad, B. O.:

Transnationaler Vergleich der

Betriebsorganisation unter

Berücksichtigung arbeitswissenschaftlicher

Ansätze (Ph.D. thesis TU-Hamburg Harburg, in print)

Kanawaty, G. and Thorsrud, E.:

Field experiences with new forms of work organization: International labor review, 120, p. $263-277,1981$

Ketchum, L.:

Sociotechnical design in a third world country: The railway maintenance depot at Sennar in the Sudan: Human relations, 37 (2), p. 135 154,1984

Nevis, E. C.:

Using an American perspective in understanding another culture: toward a hierarchy of needs for the People's Republic of China, Journal of Applied Behavioral Science. 19, 3, p. 249-264, 1983 